\title{
A construção de uma das pioneiras usinas hidrelétricas paulistas: Itatinga
}

Dossier Eletromemória: PAISAGEM E HisTóRIA

\section{Ana Luisa Howard de Castilho}

Arquiteta e Urbanista, Mestre e Doutora (USP). Consultora da CODESP - Companhia Docas do Estado de

São Paulo. Professora Universitária. São Paulo [SP] Brasil. <alhoward@analuisahoward.com.br>.

\section{Itamar Barbosa Gonçalves}

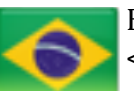

Engenheiro Industrial Elétrico. Chefe de Serviços na UHE Itatinga da CODESP. Guarujá [SP] Brasil.

<itamarbg@uol.com.br>.

\section{Resumo}

As motivações e os desafios tecnológicos que promoveram a construção da usina hidrelétrica de Itatinga e sua viabilidade na região de Bertioga [SP] foram muitos. A participação constante do Eng. Weinschenck e suas anotações, no período de 1903 até 1914, contribuíram para que a memória de sua construção pudesse ser resgatada. Também a existência de uma vila operária assegurou a permanência da maioria dos funcionários e suas famílias em Itatinga por muitos anos. A Usina passou por dois grandes processos de modernização tecnológica e permanece gerando energia até os nossos dias.

\section{Palavras-chave}

Construção civil, tecnologia, vila operária, acervo.

\section{The construction of one of the pioneers hydroelectric plants in Sao Paulo [Brazil]: Itatinga}

\begin{abstract}
The motivations and technological challenges that promoted the construction of the hydroelectric plant of Itatinga and its viability in Bertioga [State of São Paulo] region were a lot. Eng. Weinschenk's notes from the period of 1902-1914, contributed for the recovery of the history of its construction. A town was built surrounding the plant, so that all of the workers and their families remained on site for many years. The plant has undergone two major processes of technological modernization and continues to generate energy to this day.
\end{abstract}

\section{Keywords}

Civil construction, technology, company town, collection. 


\section{Introdução}

A usina hidrelétrica de Itatinga ${ }^{1}$, construída pela Companhia Docas de Santos (CDS), posteriormente herdada pela Companhia Docas do Estado de São Paulo (Codesp), destinou-se à geração de energia elétrica para o Porto de Santos e cidades relacionadas ao mesmo, como Santos e Guarujá. Também gerou energia para a construção da usina hidrelétrica de Henry Borden, em Cubatão. Em 1910, Itatinga era uma das mais importantes hidrelétricas do país, em uma época em que poucos tinham acesso à rede elétrica.

Em 1900, uma expedição capitaneada pelo Engenheiro Guilherme B. Weinschenck, buscou um local que além de possuir um manancial de água, teria o potencial para gerar energia suficiente não apenas para o Porto de Santos, mas com um excedente energético. 0 rio escolhido foi o Itatinga, e a ele foi incorporado o Rio Itapanhaú, em Bertioga. O Rio Itatinga nasce no alto da Serra do Mar e percorre vários quilômetros através de Mata Atlântica, formando cachoeiras e piscinas até desaguar no Rio Itapanhaú. No início do projeto, em 1901, o objetivo explicito de Gaffrée, Guinle \& Cia. - uma empresa composta pelos mesmos proprietários da Companhia Docas de Santos-CDS - era a utilização da energia elétrica para a modernização do Porto de Santos. Gaffrée e Guinle compraram a Fazenda Pelaes, em 1903, também em Bertioga, onde se localizavam algumas quedas d água para produção de eletricidade. A elaboração do projeto teve como exemplo algumas usinas hidrelétricas construídas nos Estados Unidos como a Bay Counties Power Co., vizinha à cidade de São Francisco na Califórnia, e a Colgate Power House, também na Califórnia.

\section{Uma obra de autor}

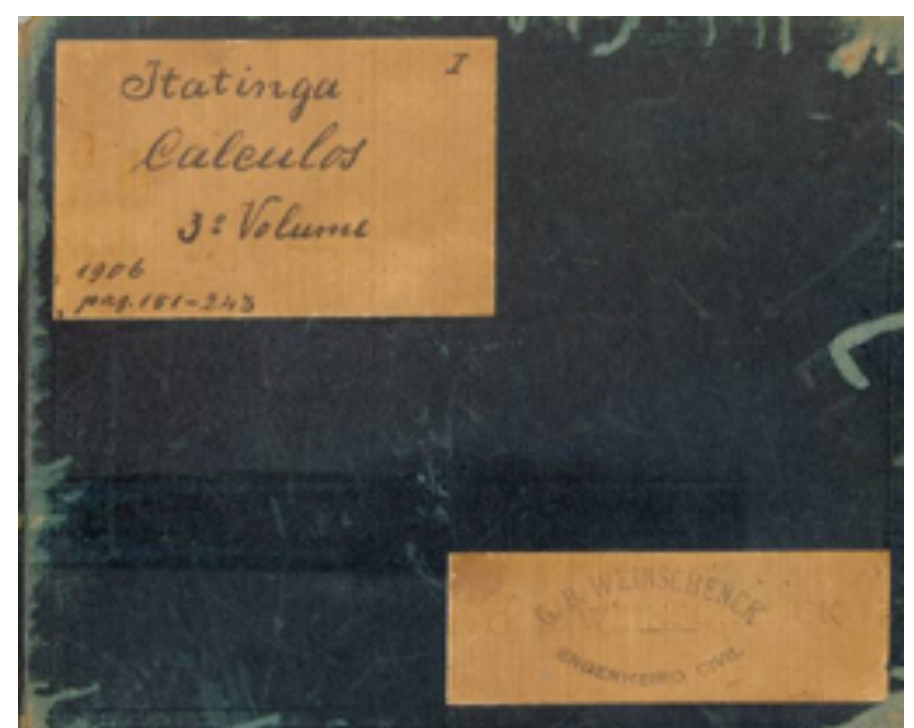

Figura 1. Um dos livros de cálculos do Eng. Guilherme Weinschenck, preservado graças aos cuidados da empresa Docas Investimentos S/A e doado para a Companhia Docas do Estado de São Paulo, em 2010. Fonte: Acervo Docas Investimentos S/A.

0 engenheiro brasileiro Guilherme Benjamin Weinschenck era um profissional raro. Havia poucos engenheiros por aqui no final do século 19 e início do século 20, e número ainda menor entre estes profissionais que seriam capazes de dominar as competências da engenharia civil, da engenharia elétrica e da atual engenharia ambiental, bem como atentar para os aspectos econômicos e administrativos do empreendimento. 0 Eng. Weinschenck concebeu e supervisionou desde as plantas (das represas, da vila de funcionários, da usina, da estrada de ferro, da linha elétrica), como todas as dimensões, formatos, cálculos de estruturas, de fluxos, força, potência, transmissão de energia, até as instruções para a drenagem da serra e da baixada do parque de Itatinga. Considerados os desafios técnicos e tecnológicos para a viabilidade da hidrelétrica na região de Bertioga, a participação do Eng. Weinschenck em todo o processo foi fundamental e graças ao encontro com suas anotações ${ }^{2}$, detalhadas nos cinco cadernos de obra, a memória dos estudos e da construção de Itatinga pode ser resgatada.

A elaboração do projeto de Itatinga teve como exemplo usinas hidrelétricas construídas no exterior, como citado acima, e foi executado com base no potencial de adaptação desses projetos para a

\footnotetext{
${ }^{1}$ A usina hidrelétrica de Itatinga está localizada a cerca de $15 \mathrm{~km}$ do município de Bertioga, Estado de São Paulo, com acesso terrestre através da Rodovia Prestes Maia, BR 101 (Santos-Rio) , km 224, pela rua Manoel Gajo, s/nº. A temperatura do ar ambiente oscila de $8^{\circ} \mathrm{C} \mathrm{a}+50^{\circ} \mathrm{C}$. A umidade relativa do ar pode ser considerada entre 70 e 100 porcento.

2 Os cadernos - do primeiro de 1903 até o último de 1914 - se encontravam no Rio de Janeiro, no escritório da Docas Empreendimentos, uma empresa que herdou alguns documentos da Companhia das Docas de Santos - CDS. Atualmente, estão sob a guarda da equipe da presidência do Porto de Santos.
}

Labor \& Engenho, Campinas [SP] Brasil, v.9, n.1, p.73-81, jản./mar. 2015. Disponível em: www.conpadre.org 
realidade nacional com transmissão a 44.000 volts. Por meio da pesquisa, mas principalmente de deduções empíricas, concluímos que a obra de Itatinga deve ter sido executada concomitantemente em pelo menos quatro canteiros de obra, a saber: o reservatório, a câmara d'água e a usina. Enquanto as obras avançavam no reservatório, a 724 metros acima do nível do mar, outro grupo de trabalhadores preparava a construção da câmara d'água a 640 metros acima do nível do mar, para onde seriam conduzidos os tubos que alimentariam a usina propriamente dita, um terceiro grupo preparava o projeto da casa de força e um último grupo se preocupava em abrir a mata para instalar os postes da linha de transmissão. A construção da vila de casas também foi inserida na sequência desses grupos de construção. Para tal, os trabalhadores transpuseram mangues, matas e serras íngremes, além de enfrentar o mosquito vetor da malária. Não encontramos registros de quantas vidas foram perdidas neste processo, mas certamente houve perdas fatais. No entanto, a logística do projeto era bem estruturada e, apesar da dificuldade em obtenção de tecnologia na época, o projeto foi executado em tempo recorde, iniciado após 1905 e com a primeira turbina funcionando, ainda em 1909. Após o início oficial da operação da usina, em 10 de outubro de 1910, e mais de um século depois, nenhuma pane, nenhuma correção, nenhum imprevisto, nenhum problema técnico, nem ambiental escapou às pranchetas do engenheiro.

É extraordinário constatar que a força das águas que deslizam pelas tubulações da Usina de 1910 ainda movem as máquinas e equipamentos que põem em funcionamento e fornecimento estratégico parte da energia elétrica do maior porto da América do Sul. É mais surpreendente ainda que a realização desta PCH foi obra de brasileiros no início do século passado, pois apesar de sobrenomes inglês (Guinle) e alemão (Weinschenck), estas famílias já estavam estabelecidas há alguns anos no sul do Brasil.

O período que precedeu os estudos para a construção da usina de Itatinga foi bastante movimentado no mundo, tanto para a teoria quanto para a pesquisa científica, ambos fundamentais para o desenvolvimento tecnológico. Foram construídas diversas PCH entre 1880 e 1900, objetivando fornecer energia para a iluminação pública, e outras atividades econômicas como: a mineração, as fábricas de tecido, as serrarias, os produtos agrícolas (MAGALHÃES, 2010. p.49), modais de transporte - em 1900 foi inaugurada a primeira linha de bondes elétricos em São Paulo - e os portos. Para obter concessões e executar novos empreendimentos, os dirigentes da Companhia Docas de Santos (CDS) foram observadores e perspicazes, adaptando-se à conjuntura econômica da época. Havia potencial de crescimento do setor de serviços públicos no Brasil e diversos grupos de investidores nacionais e internacionais reconheceram este potencial, e se interessaram em propor atividades nesta área. No entanto, um setor em particular atraiu alguns grupos de investidores: a produção e a distribuição de energia elétrica. Dentre eles figurava a companhia Light \& Power Co., empresa que pertencia ao grupo de investidores norte-americanos e canadenses cujo representante no Brasil era Alexander Mackenzie, e outro grupo, de capital majoritariamente nacional, representado pela Guinle \& Co., que passou a ser denominado Companhia Brasileira de Energia Elétrica (CBEE) em $1^{\circ}$ de junho de 1909.

Além da relevância da usina hidrelétrica de Itatinga quanto à sua forma de concepção e construção, pode-se afirmar que ela representa um empreendimento precioso para a história da industrialização brasileira. Sua concepção partiu do modelo de usina hidrelétrica a fio d'água e se materializou por meio do desvio de parte do rio Itatinga que segue por gravidade, e por um canal coberto desde o reservatório até a câmara d'água. Da câmara d’água, o volume de água é divido por cinco linhas de tubos, onde a velocidade e a força são ampliadas e chegam na casa de força (usina), também conhecida como Casa de Pedra, como explicaremos a seguir.

\section{Uma obra coletiva}

Apesar das possibilidades que a emergente tecnologia oferecia no início do século 20, tanto no Brasil como em outras partes do mundo, a técnica e a tecnologia puderam conviver. Foi com fundamentos da técnica que a expedição de Guilherme Benjamin Weinschenck adentrou a Mata Atlântica a fim de elaborar um estudo que refletiria a visão empreendedora do investimento e um profundo conhecimento sobre a engenharia, que constituiria a base tecnológica. Após a escolha do Rio Itatinga, e durante os anos 1903 e 1904, a expedição marcou oito poligonais que definiram a área de estudo. Estas poligonais estavam circunscritas na área que compreendia desde a Fazenda Pelaes até a margem esquerda do Rio Itapanhaú. Cerca de 25 quilômetros em picadas foram abertos na mata no sentido de viabilizar o 
acesso aos vários pontos do rio, bem como para medir os níveis e a velocidade do fio da água entre alguns pontos, a relação do desnível do terreno entre a cascata e a futura câmara d'água, e os cálculos considerando toda força disponível no rio (CASTILHO, 2010. p.33).

O mapeamento utilizado na época, foi a carta da Comissão Geográfica e Geológica de São Paulo. Esta base cartográfica fundamentou o primeiro esboço do traçado das linhas de postes que ligariam a usina ao Porto de Santos. Um dos maiores desafios do projeto de Itatinga foi a travessia da linha sobre o canal de Bertioga e sobre o canal de Santos. Para tal, existem registros nos cadernos do Eng. Weinschenk de diversos estudos no sentido de solucionar este problema.

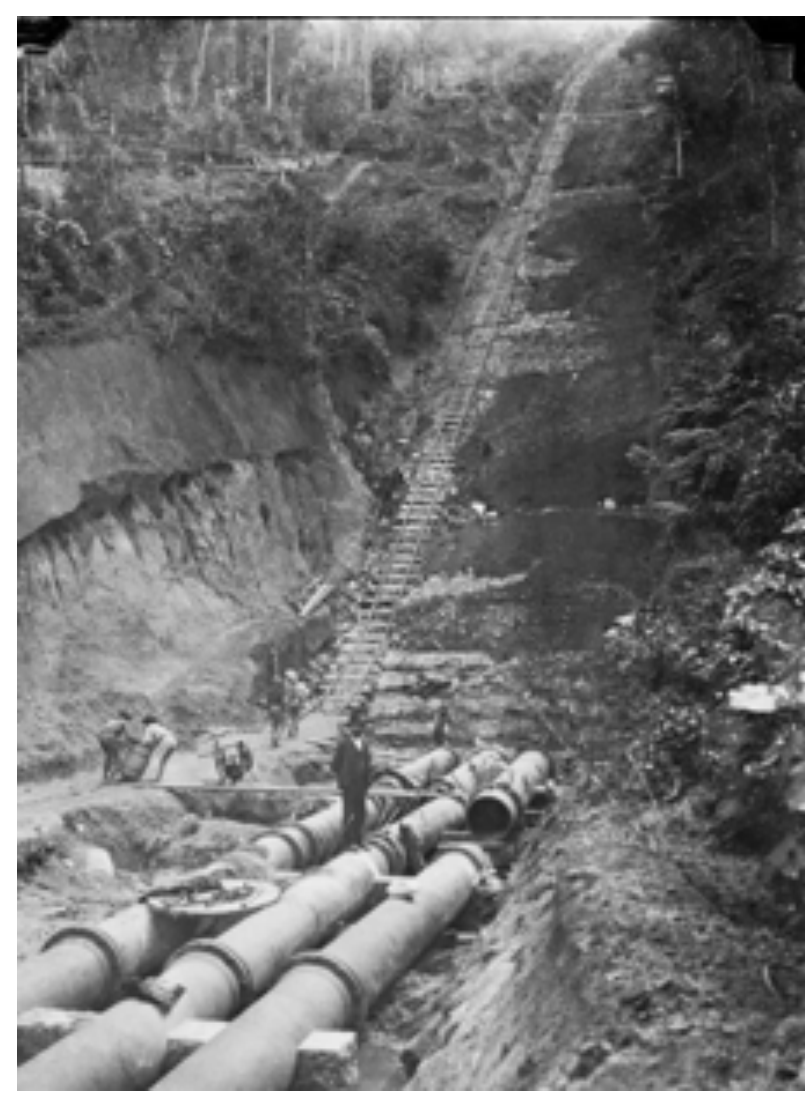

Figura 2. Início da instalação da linha de tubos, próximo à casa de força ou usina (s./d.). Fonte: Acervo Docas Investimentos S/A.

A proposta de delimitação da barragem do reservatório teve de considerar a melhor área passível de alagamento e essa definição também foi condicionada à existência do canyon do Itatinga. Não foram encontrados os registros que afirmam qual foi a data de conclusão do reservatório, mas certamente foi anterior a 1909. Poucos exfuncionários da hidrelétrica, e que trabalharam na área da Usina até a década de 1950, permaneceram vivos para que obtivéssemos depoimentos que comprovassem algumas hipóteses. Encontramos o Sr. Francisco Vieira de Barros, quem afirmou sobre a existência de imigrantes russos e espanhóis, dentre os operários da construção do reservatório e da câmara d'água. Em seu depoimento, disse que os espanhóis eram exímios na execução da cantaria em pedra - construções como as existentes na câmara d’água e cobertura do canal e no túnel sob a cachoeira. Nos anos 1940, os russos foram trabalhar na serra ${ }^{3}$ e constituíram a maioria dos funcionários que construíram o túnel escavado na rocha de 940 metros que conduz a água derivada do canal principal. 0 túnel foi construído por causa dos desmoronamentos na encosta, e parte da água que corria pelo canal principal foi desviada. 0 canal principal é uma ligação exclusiva entre a reservatório e a câmara d'água, que foi construído aberto e media 1 metro de altura por 1,5 metro de largura com extensão de 3.034 metros sobre um declive de 3,5\%. Por volta dos anos 1910, logo após o início do funcionamento da usina, o canal teve de ser coberto com uma espessa camada de pedra para proteger a água das folhas das árvores, dos gravetos e de grandes pedras que rolavam morro abaixo e causavam danos ou interrompiam o funcionamento da usina" (CASTILHO, 2010. p.40).

Os canais chegam à câmara d'água e de lá seguem por cinco linhas de tubos de aço fundido com encaixe do tipo ponta e bolsa. Na ocasião da construção da Usina, havia grande preocupação quanto à resistência dos tubos que conduziriam as águas. Para não haver problema no futuro próximo da usina, a CDS adquiriu algumas peças extras de tubos e estas jamais foram utilizadas e ainda se encontram no Posto da Fazenda, uma área próxima do Portinho, pertencente à usina. Os tubos, cujo diâmetro são variáveis, com 900, 800, 700 ou 600 milímetros, não têm costura e seus encaixes são vedados com chumbo derretido. Para a instalação da linha de tubos, a técnica foi encaixá-los desde a casa de força no sentido da câmara d’água. Este procedimento foi registrado em fotografia na época da construção.

\footnotetext{
${ }^{3}$ Provavelmente foram isolados devido à dificuldade de comunicação. No depoimento, o Sr. Francisco ainda completou: eles bebiam muito. Pois bem, estavam isolados e distante de suas famílias, parece coerente que o lazer se restringisse às bebidas alcoólicas.
} 
A instalação da linha de tubos considerou ancoragens em pedra, bem como maciços em pedra que apoiam os tubos. 0 conjunto constituído pelo tipo de encaixe e pelos maciços impede o escorregamento ou a deformação dos tubos em decorrência da pressão e da velocidade da água pelos mais de 2 quilômetros e em curvas, devido à característica da topografia. A pressão da água tem muita força nas curvas e isso facilita o deslocamento dos tubos. Além das ancoragens, também foram instaladas válvulas automáticas em dois pontos da linha de tubos, próximos à camara d água e no ponto intermediário, que se fecham em caso de ruptura de um tubo, e abrem aliviando a pressão em caso de golpe de ariete.

Nas proximidades da casa de força, uma linha de tubo interliga as cinco tubulações que descem da câmara d água na casa de válvula - que fica ao lado do salão de máquinas, onde estão localizadas as turbinas e os geradores - para que qualquer linha de tubo possa servir as cinco turbinas. No princípio, a casa de válvulas tinha divisórias e portas para o salão de máquinas. Estas divisórias foram retiradas para melhorar a ventilação de toda a área na casa de força. A casa de força veio a se chamar Casa de Pedra pelos funcionários e moradores de Itatinga devido à técnica construtiva adotada na construção de algumas usinas hidrelétricas, inclusive desta. A pedra é um material construtivo que além de ser de fácil acesso na encosta da serra também é resistente e a melhor alternativa para a manutenção da estabilidade de edifícios como a casa de força, já que a mesma é destinada ao abrigo de equipamentos que não podem sofrer alterações pelo recalque ou rebaixamento causados pelo movimento natural do solo (CASTILHO, 2010. p.47).

Para vencer os 640 metros de altura da casa de força até a câmara d’água, foi instalado um trolley baseado em uma estrutura com 3 fileiras de bancos e uma caixa para carregar algum material ou peças. 0 trolley funciona por meio de um sistema de cabos de aço, sem contrapeso e com apoio em 6 máquinas fixas ${ }^{4}$. Essas máquinas funcionaram à carvão até o início da operação da usina hidrelétrica.

A obra do complexo da hidrelétrica de Itatinga promoveu diversos ganhos ambientais que merecem ser destacados, como o sistema de drenagem das águas pluviais, tanto na área imediata à casa de força, como em toda a ligação com a câmara d’água até o reservatório. 0 sistema de drenagem também é imprescindível para o acesso pela via férrea à vila de Itatinga. 0 acesso de materiais e pessoas até $\mathrm{a}$ área da hidrelétrica se deu pelo Rio Itapanhaú. A distância entre o rio e a usina é aproximadamente de sete quilômetros e uma via férrea foi construída para vencer esta distância e transportar pessoas e materiais. A linha férrea é o modal de transporte que estruturou e estrutura boa parte das necessidades de quem viveu ou vive e trabalha em Itatinga. A pesquisa ainda não revelou os registros sobre esta construção, mas sabe-se que a CDS já comprava locomotivas a vapor no final do século 19 para utilizá-las no Porto de Santos. Antes do funcionamento da primeira turbina, também foi preciso importar carvão para o funcionamento das locomotivas, tanto aquelas que operavam no Porto quanto aquelas de Itatinga. Somente foi possível contar com o apoio de bondes elétricos após a conclusão e operação da usina. Esta alteração diminuiu os custos de operação e vinculou Itatinga ao princípio do uso de uma matriz energética limpa e renovável, isto já no início do século 20.

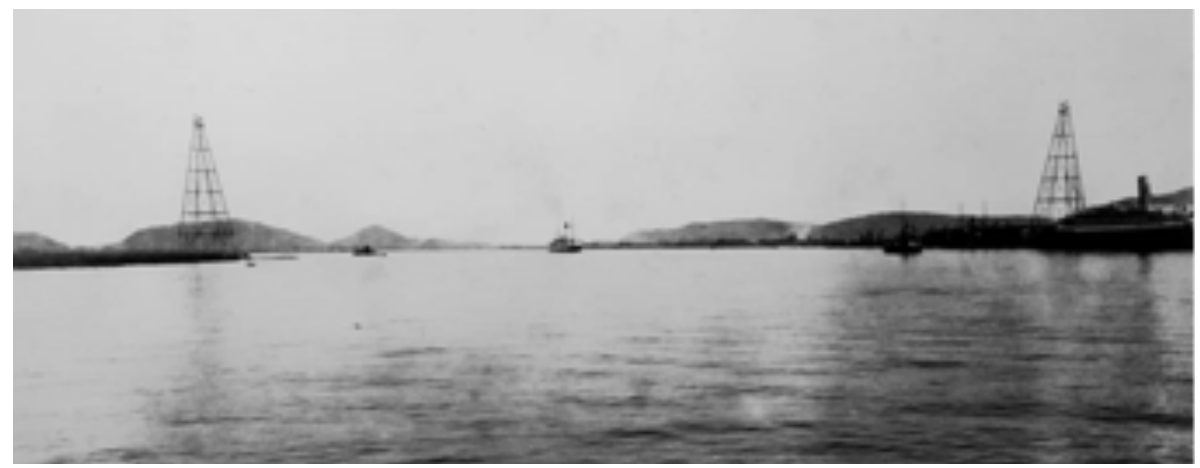

Figura 3. 0 traçado da linha de postes foi baseado na carta da Comissão Geográfica e Geológica de São Paulo. Acima, vemos como foi solucionado um dos dois grandes desafios encontrados, ainda em 1903. A transposição da energia pelo canal do Porto de Santos, com o objetivo de chegar até a casa de força que fica na margem direita do canal, e a travessia dos cabos do canal de Bertioga, que fica próxima ao monte Cabrão. Fonte: Acervo Docas Investimentos S/A.

\footnotetext{
${ }^{4}$ Localmente conhecidas como guinchos.
} 
Aproximadamente 30 quilômetros de linhas de transmissão ligam a usina de Itatinga ao Porto de Santos, passando pelo Canal de Bertioga e pelo Canal de Santos. Como mencionamos, este foi um desafio do projeto. No caso de Santos, são atravessados 520 metros de vão livre e as torres medem 90 metros de altura para permitir a passagem dos navios. Além da transmissão de energia, dois legados: as torres da margem esquerda - Guarujá - e da margem direita, em Santos. As torres se tornaram emblemáticas e passaram a ilustrar os cartões postais da cidade.

\section{A vila dos operários}

A existência de uma vila operária na usina hidrelétrica de Itatinga está fundamentatada em um formato bastante usual e replicado na maioria das empresas que se distanciaram dos centros urbanos e que necessitavam de mão de obra, entre os séculos 18, 19 e início dos 20: as Company Towns ${ }^{5}$, ou na versão nacional, as Cidades-Empresa. Estas simbolizaram a modernidade e o avanço das fronteiras mundiais do capitalismo industrial (CASTILHO, 2010. p.101).

No começo das obras em Itatinga a diretoria da CDS, que já havia construído habitações para seus funcionários na área do Porto de Santos, ordenou que fossem construídas algumas casas para abrigar seus funcionários, especialmente aqueles que permaneceriam no canteiro durante as obras, bem como, no início da operação da hidrelétrica. A Vila de Itatinga passou a constituir um importante exemplar de vila operária pertencente a um porto. Não se sabe ao certo quantas casas foram construídas nesses primeiros anos, pois os registros do conjunto não foram descobertos até este momento. Entretanto, muitas unidades habitacionais foram objeto de intervenção, como verificado na cópia de seus projetos encontrados no início de 2013. A comparação da técnica construtiva utilizada nas casas de alvenaria e a proposta para a casa de força, indica que a construção da vila de Itatinga tenha sido iniciada pelas casas de alvenaria, com alicerce de pedra, tal qual a casa de força. Estas casas abrigaram os engenheiros e os funcionários graduados. Já as casas no reservatório e na câmara d'água abrigaram os operários que fiscalizavam esses postos e suas famílias. Na maior parte da Vila, as unidades habitacionais foram construídas em madeira e abrigavam os operários que executavam diversas atividades na hidrelétrica. No caso das unidades em madeira, o alicerce era constituído com base em pilares de sustentação de alvenaria nos cantos da construção e preenchido com ripas de madeira em toda a volta. As casas tinham de estar isoladas do chão para que a madeira das paredes não apodrecesse. Essa era uma técnica muito conhecida em diversos países europeus e nos Estados Unidos. Entretanto, o ripado de madeira parece ser uma adaptação brasileira, pois é contraindicado para as edificações em madeira devido à possibilidade de absorver a humidade da terra por capilaridade. Os funcionários solteiros moravam em uma residência coletiva conhecida como Barracão, também em madeira. A técnica da madeira facilitou as intervenções futuras. Existem registros das reformas internas destas casas por meio da alteração dos painéis de madeira. 0 requisito para ocupar uma unidade habitacional em Itatinga era ser funcionário da CDS.

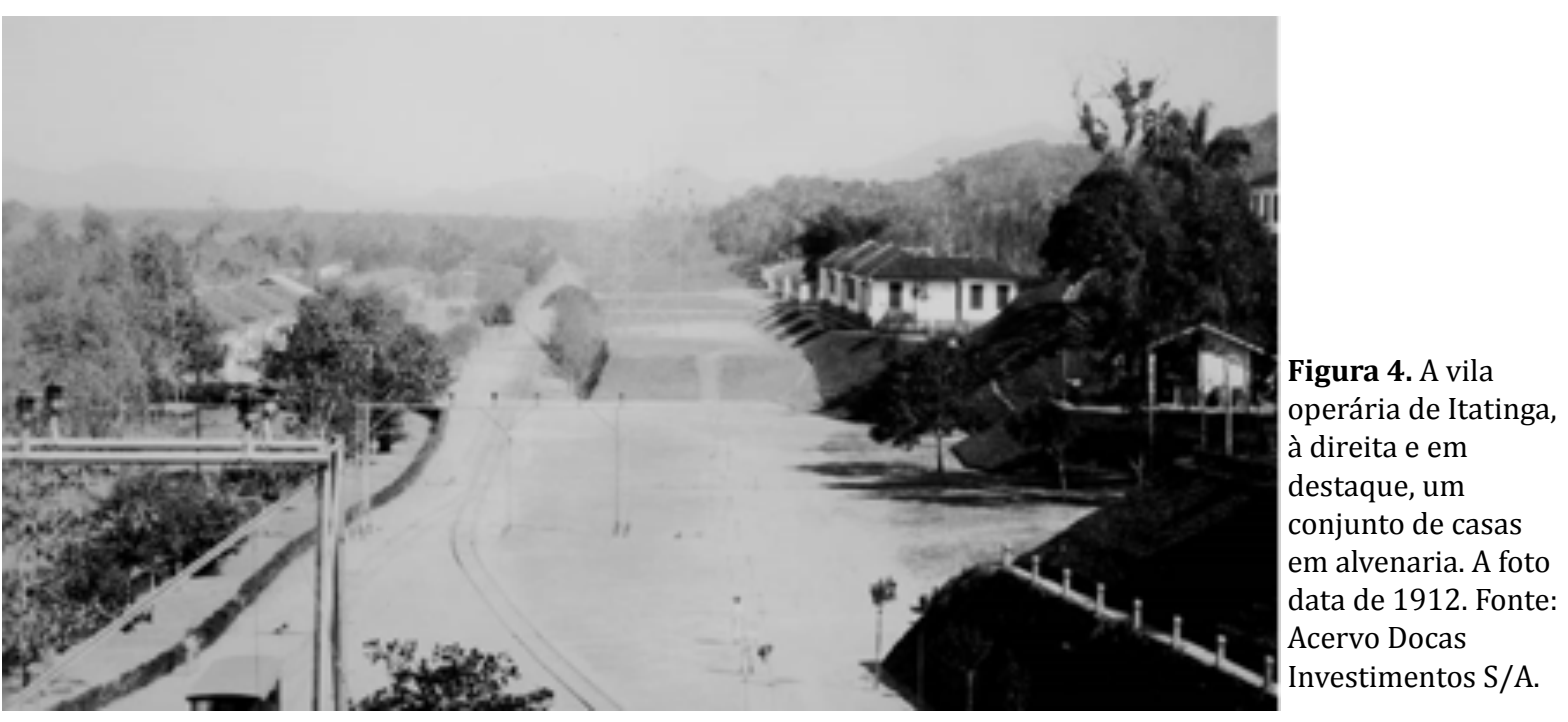

\footnotetext{
${ }^{5}$ Nota do Editor. Ver Labor \& Engenho, v.8, n.4, 2014: Dossier Company Towns. Disponível em: www.conpadre.org
} 
Além das casas, a Vila possuía uma infraestrutura de serviços invejável para os padrões da época, especialmente comparando com o povoado da vizinha Bertioga. A vila de Itatinga, em plena vitalidade, tinha: um armazém de gêneros alimentícios sortido, subsidiado e supervisionado pela CDS; uma padaria, uma escola fundamental para os filhos dos funcionários, um clube, inaugurado em 1928, com o seu campo de futebol e outros equipamentos de lazer; e um posto médico para o atendimento emergencial e especializado. A Vila chegou a ter 350 moradores que foram distribuídos em 70 casas que ladeavam a via férrea e seu bondinho.

A via férrea e a linha de transmissão constituíram os elementos estruturadores da vila de Itatinga. A via férrea cruza por terra entre o Porto da Usina, ou Portinho, até o início da linha de tubos, e a linha de transmissão percorre o espaço aéreo no mesmo trajeto da via férrea, até a Fazenda Pelaes. Essas duas linhas, uma no chão e outra no ar, cortaram o terreno plano ao meio e para tirar melhor proveito dessa área e construir casas confortáveis e com quintais, a opção encontrada foi construir duas fileiras de casas, uma em frente à outra e com as duas linhas no centro. Essa é a marca na paisagem que permanece na até hoje.

A via férrea e o rebocador foram imprescindíveis para a vida na Vila e usina hidrelétrica de Itatinga. Não havia estradas de acesso até Bertioga até os anos 1970, portanto tudo que chegava ou saía de Itatinga passava pelo Canal de Bertioga e pelo Rio Itapanhaú até o porto da usina.

\section{Da modernização à memória tecnológica da Usina Hidrelétrica de Itatinga}

A Usina Hidrelétrica de Itatinga passou por dois grandes processos de modernização tecnológica desde a sua construção. 0 primeiro, nos anos 1950, renovando alguns equipamentos e componentes, como: o quadro de comando; a instalação de um sistema de para-raios destinado às máquinas; a reforma da ligação das linhas de transmissão à terra; as máquinas excitadoras que passaram das excitatrizes independentes para as excitatrizes GE acopladas ao eixo; e a substituição de dezesseis transformadores monofásicos. E, entre 2012 e 2013, a segunda, por meio da instalação de sistemas de regulação digitais de velocidade; dos sistemas de excitação para as máquinas síncronas acopladas aos eixos dos geradores, relés de proteção, medidores, disjuntores; e do cabeamento destes sistemas, pela ABB Ltda. Este último processo de modernização alterou algumas composições e layout interno de equipamentos e componentes no interior da casa de força. Contudo, todo o material retirado foi resguardado e está aguardando um novo espaço expositivo, organizado para assegurar o acervo sobre a memória tecnológica da Usina Hidrelétrica de Itatinga.

Devido à pesquisa para a produção do livro "Itatinga, a hidrelétrica e seu legado" (CASTILHO, 2010) bem como, a montagem da exposição "A Joia do Itatinga", alguns equipamentos da hidrelétrica foram descobertos. Parte destes equipamentos foram adquiridos durante sua construção, e outros, mais recentes, obtidos durante o primeiro processo de modernização. Cada equipamento foi analisado por uma espécie de junta de especialistas, composta por trabalhadores atuais e ex-trabalhadores da Usina, ocasião em que se concluiu que havia um considerável acervo guardado para a reposição e outras peças usadas e que haviam sido preservadas. Com o embrião de um acervo e a perspectiva da modernização tecnológica, a necessidade de um debate sobre $\mathrm{o}$ assunto foi ampliada.

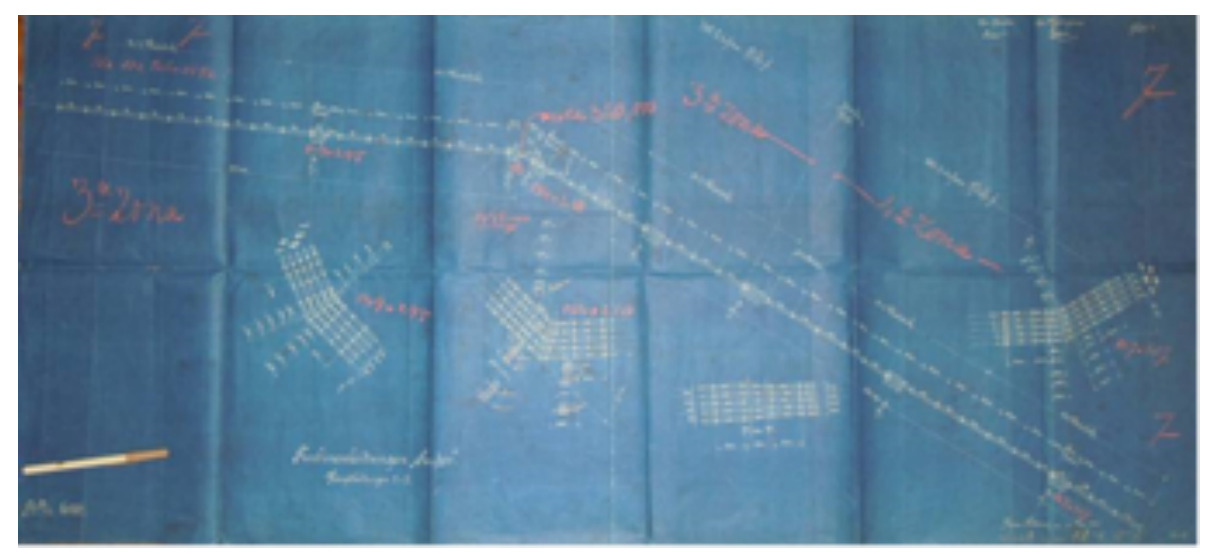

Figura 5. Um exemplo de documento encontrado na usina: a cópia manuscrita em linho data de 1905 e apresenta uma das etapas do projeto executivo da linha de tubos. Executada em Hamburgo, Alemanha. Fonte: Acervo da Usina Hidrelétrica de Itatinga (Codesp).

\footnotetext{
${ }^{6}$ http://www.ajoiadoitatinga.com.br
} 
Para abrigar o acervo material e documental, decidiu-se pela ocupação dos edifícios na vila de Itatinga que estavam sem uso definido ou com uso não criterioso ameaçando a conservação dos mesmos. A definição pela utilização dos edifícios da vila se deu devido à possibilidade de separar, fisicamente, o espaço de produção, do espaço reservado para o acervo de equipamentos, componentes e documentos. Partiu-se então para a seleção das edificações sempre com vistas ao acervo disponível, isto é, aquele existente e o que vem sendo disponibilizado por ocasião do processo de modernização da Usina.

Nos critérios de identificação dos edifícios foi privilegiada a seleção daqueles que necessitam de intervenção para que permaneçam preservados. Um dos objetivos da proposta de ocupação dos edifícios da vila de Itatinga consiste na economia da aplicação dos recursos financeiros que a Codesp faz no que tange à conservação dos imóveis, na medida em que o uso das edificações colaborará para a sua preservação estrutural e física, eliminando as manutenções frequentes que são geradas pelas estruturas edificadas vazias ou não adequadamente ocupadas.

\section{Conclusões}

Avaliar o patrimônio representado pela construção da Usina Hidrelétrica de Itatinga em Bertioga, passa pela consideração de três grandes valores:

1. o significado econômico do empreendimento liderado pela Companhia Docas de Santos;

2. sua relação integrada e produtiva com o meio ambiente;

3. sua contribuição inestimável para a debutante industrialização brasileira.

Para compreender a hidrelétrica como patrimônio econômico, basta estimá-la em valores monetários, e isso pode partir de um cálculo baseado em uma conta de luz de um consumidor doméstico na cidade de São Paulo. Considerando esta base de cálculo, é possível concluir que nos quase 105 anos de funcionamento, a Usina gerou por volta de 4 bilhões de reais líquidos.

Itatinga é um patrimônio natural, pois ocupa e preserva uma área de relevância paisagística, ecológica e histórica, cobrindo os diversos nichos que caracterizam o bioma da Mata Atlântica.

O conceito de patrimônio industrial é recente. 0 complexo da usina hidrelétrica de Itatinga se enquadra perfeitamente nessa categoria, pois possui um conteúdo histórico relevante, seu legado tecnológico é notável, tem qualidades e estética arquitetônica singulares e é uma fonte de informações importantes para a história da tecnologia brasileira. 0 complexo de Itatinga, além de edifícios, maquinaria, oficinas, centros de produção, transmissão e utilização de energia, possui também sistema de transporte e abastecimento de água potável próprios, e uma vila operária com equipamentos para atividades sociais.

A natureza forneceu os recursos para a instalação da usina hidrelétrica. Nascida para acelerar o processo de modernização do Porto de Santos, Itatinga iluminou boa parte da baixada santista, bem como parte da cidade de São Paulo quando foi necessário. Tudo isso colaborou diretamente para a preservação e conservação da natureza local.

Testemunho histórico de um empreendimento econômico, ambiental e socialmente exemplar, Itatinga é uma joia que deve ser preservada, sobretudo, como modelo de desenvolvimento sustentável para o país (CASTILHO \& POMPÉIA, 2011).

\section{Referências}

ARQUIVO Nacional.Ata da Primeira Reunião da Assembleia de Constituição. Diário Oficial da União, 4 jul. 1909, p. 4247-9.

BARROS, G.M. Guilherme Guinle 1882-1960. Ensaio Biográfico. Rio de Janeiro: Agir, 1982.

BERENGER, J. de M. Usina hidroelétrica de Itatinga. Revista GE, p. 29-31, jul. 1954. 
CASTILHO, A. L. H. Itatinga: a hidrelétrica e seu legado. São Paulo: Editora Neotropica, 2010.

CASTILHO, A.L.H.; POMPÉIA, M. Texto para a Exposição “A Jóia do Itatinga”, 2011.

CODESP irá restaurar Vila e Usina de Itatinga. A Tribuna, Santos, 29 dez. 2009, p. C2 Porto e Mar.

CRAWFORD, M. Building the Workingman's Paradise. The Design of American Company Towns. London, New York: Verso, 1985.

GAMA, R. A tecnologia e o trabalho na história. São Paulo: Nobel/Edusp, 1986.

Itatinga. A Tribuna, Santos, 25 jul. 2010, p.A12 Baixada Santista.

KALTMAN, H. Docas de Santos: uma empresa através dos séculos. Rio de Janeiro: Agir, 2000.

LEGISLAÇÃO portuária. Edição comemorativa da abertura dos portos. Rio de Janeiro: Departamento Nacional de Portos, Rios e Canais, 1958.

LOBO, H. Docas de Santos: suas origens, lutas e realizações. Rio de Janeiro: Typ. do Jornal do Commercio, 1936.

MAGALHÃES, Gildo. Força e luz: eletricidade e modernização na República Velha. São Paulo: Editora Unesp: Fapesp, 2000.

MARCOVITCH, J. Pioneiros e empreendedores: a saga do desenvolvimento no Brasil. São Paulo: Edusp, 2005

MEMORIAL Madeley. In: A Crise do Porto de Santos, Estudo Preliminar Elaborado pela Associação Commercial de São Paulo: s.l., s.e.,1925, p. 237-238.

Rapport General sur les Usines, l'Organisation, les Concessions et les Franchises de la Companhia Brazileira de Energia Electrica. Publié par le Bureau de Londres avec l'approbation du Siège Social de la Société à Rio de Janeiro, s/d.

SAES, A.M. Luz. leis e livre-concorrência: conflitos em torno das concessões de energia elétrica na cidade de São Paulo no início do século XX. 2007. Disponível em: http://www.scielo.br/pdf/his/v28n2/08.pdf. Acesso em: 3 ago. 2010.

Industrialização e política local: constrangimentos na expansão da Companhia Nacional de Tecidos de Juta no início do século XX. In: XIII Econtro de História Anpuh-Rio. 2008. Disponível em: http:// encontro2008.rj.anpuh.org/resources/content/anais/1208480198_ARQUIVO_AnpuhRiodeJaneiro.pdf. Acesso em: 9 ago. 2010.

SANTOS, F. M. Historia de Santos, 1532-1936. São Vicente: Caudex, 1986.

VARGAS, M. História da ciência e da tecnologia no Brasil: uma súmula. São Paulo: Humanitas, 2001.

WEINSCHENCK, G.B. Itatinga cálculos Provisórios $1^{\circ}$ volume - 1903-1904. Manuscritos.

—. Itatinga cálculos $3^{\circ}$ volume - 1906. Manuscritos.
. Itatinga cálculos $4^{\circ}$ volume - 1907. Manuscritos.
. Itatinga cálculos $5^{\circ}$ volume - 1908. Manuscritos.

WEINSCHENCK, G.B. Central electrica em Santos. Distribuição de energia electrica. Manuscritos, s/d. 